\title{
Oral Manifestation for Patients with Thyroid Dysfunction and it's Management in Dental Clinic -A Review
}

\author{
Anas Al-Yasiry M.Sc ${ }^{1}$ Zainab Mahmood Al-Jammali M.Sc ${ }^{2}$ \\ ${ }^{1}$ Department of Basic Science College of Dentistry, University of Babylon, Iraq. \\ ${ }^{2}$ Department of Prosthodontics/College of Dentistry, University of Babylon, Iraq.
}

$\underline{\text { Review Article }}$

Address for Correspondence Author

Dr. Zainab Mahmood Al-Jammali, Department of Prosthodontics/College of Dentistry, University of Babylon, Iraq.

E-mail: zainab.jouid@yahoo.com

Crossref doi: https://doi.org/10.36437/ijdrd.2020.2.1.0

\section{ABSTRACT}

Aim: Review the most important management of thyroid gland dysfunction. The thyroid is the most important gland is a bilobular structure located on both sides of the trachea. Thyroid functions disturbance most the second common of the endocrine system disorder, it's increased among women it about $5 \%$ of the population women have thyroid dysfunction, and about $6 \%$ can clinically be detected of the thyroid nodules by palpation.

Conclusion: The dentist determined thyroid dysfunction and avoid dental complications result in a dental clinic by taking information also take care about cardiovascular statuses due to some patients suffer atrial fibrillation with anticoagulation therapy, that made need antibiotic prophylaxis before treated. The hypothyroidism Patients sensitive to barbiturates and central nervous system depressants so the drug used for medications very little. The dentist must be given fluoride as a drug as a treatment for hyperthyroidism patients due to the fluoride act to reduce thyroid activity by its ability to mimic the action of thyrotropin (TSH). fluoride linked to thyroid problems. A patient must avoid the effect of fluoride on their thyroid can utilize from fluoride-free Toothpaste like CariFree, an oral neutralizer gel.

Keywords: Oral, Thyroid, Dysfunction, Management, Dental, Clinic.

Introduction: The thyroid is the most important gland is a bilobular structure located on both sides of the trachea. Thyroid functions disturbance most the second common of the endocrine system disorder, it's increased among women.[1]it about5\% of the population women have thyroid dysfunction,[2,3] and about $6 \%$ can clinically be detected of the thyroid nodules by palpation.[4] 15\% of the people have abnormal thyroid anatomy on physical examination, without complete a diagnostic evaluation. Also, many people affected by undetected cases.[2] that means this case with hypothyroidism or 
hyperthyroidism undiagnosed can be seen in the dental clinic.[4] The American Thyroid Association's Guidelines suggested take for screening model for the patients that help for the detection of Thyroid Dysfunction[5-8], the level screen starting at 35 years and it every 5 years made, and the patients have a serum thyroid-stimulating hormone exanimate also regardless of gender.

The family history record and the risk factor for thyroid dysfunction like diabetes mellitus, pernicious anemia, history for surgery, intake of iodine-containing medications, radiation to the head and neck region or familiar history for thyroid disease autoimmune disease.[8]

The screening started for the thyroid by examination of the head and neck, the thyroid gland examinant by the patient's head must be extended to one side. The examiner palpated the gland by both hands using the fingers then asked from the patient to swallow, to evaluate the anatomical extent of the lobules by using the last three fingers of one hand with a note the right lobule is larger than the left, in healthy patients can't observe the gland on relaxation.

\section{The Oral Manifestations for the Hypothyroidism Patients}

The hypothyroidism is decreased in hormone production and function, many reasons may cause hypothyroidism such as Hashimoto's disease, surgery, radioactive iodine, and pharmacological agents. The patients with hypothyroidism suffer from slow metabolic rate, intolerance to cold, lethargy, weight gain, puffiness of the face and eyelids and dry and cool skin also the blood pressure is normal, but the slower in heart rate. The oral manifestation for children characterize by macroglossia, thick of the lips, malocclusion and delayed in the eruption of teeth. The reason for the thick of the lips and macroglossia accumulation of subcutaneous like mucopolysaccharides, glycosaminoglycan which cans decreased in the degradation of these substances.

Also, craniofacial growth and dental development effected with hypothyroidism causes a dissociation of ramus growth and the internal aspect of the ramus failure for normal resorption result in insufficient space for eruption of mandibular second molars that cause impaction of the mandibular second molars[5] anther symptom like delayed wound healing, altered tooth morphology and poor periodontal health,[6]. The dentist determined thyroid dysfunction and avoid dental complications result in a dental clinic by taking information also take care about cardiovascular statuses due to some patients suffer atrial fibrillation with anticoagulation therapy, that made need antibiotic prophylaxis before treated.[11] The hypothyroidism Patients sensitive to barbiturates and central nervous system depressants so the drug used for medications very little. [6,12].

\section{The Oral Manifestations for the Hyperthyroidism Patients}

The hyperthyroidism is unregulated increased for thyroid hormone production. The patients with hyperthyroidism suffered from intolerance to heat, weight loss, increased appetite, emotional instability, tremor, increased cardiac output sinus tachycardia, marked chronotropic and ionotropic, systolic heart murmur and hypertension[7]. Also the oral manifestation for these patients is increased exposed to caries and periodontal disease, osteoporosis in maxillary or mandibular, enlargement occur in extraglandular thyroid tissue (lateral posterior tongue), the dental eruption accelerated [8]. The hyperthyroidism patients suffer burning pain in the mouth dry mouth due to Sjogren's syndrome[4] In dental clinic hyperthyroidism patients suffer from stress, anxiety and the Epinephrine used in local anesthesia is contraindicated, so that need used local anesthesia without Epinephrin.[17] The dentist must be given fluoride as a drug as a treatment for hyperthyroidism patients due to the fluoride act to 
reduce thyroid activity by its ability to mimic the action of thyrotropin (TSH). fluoride linked to thyroid problems. A patient must avoid the effect of fluoride on their thyroid can utilize from fluoride-free toothpaste like Carifree, an oral neutralizer gel.[18]

\section{References}

1. Larsen PR, Davies TF, Hay ID. The Thyroid. In: Williams RH, Wilson JD, Foster DW, Kronenberg HM, editors. Williams Text book of Endocrinology. 9th ed. Philadelphia: Saunders; 1998. p. 389-416.

2. Pyle MA, Faddoul FF, Terezhalmy GT. Clinical implications of drugs taken by our patients. Dent Clin North Am 1993;37: 73-90.

3. Klein I. Thyroid hormone and the cardiovascular system. Am J Med 1990;88: 631-7.

4. Pinto A, Glick M. Management of patients with the thyroid disease: Oral health considerations. J Am Dent Assoc 2002;133: 849-58.

5. Ladenson PW, Singer PA, Ain KB, et al. American Thyroid Association guidelines for detection of thyroid dysfunction. Arch Intern Med2000;160:1573-5.

6. Wartofsky L. Update in endocrinology. Ann Intern Med 2001;135: 601-9.

7. Bagchi N, Brown TR, Parish RF. Thyroid dysfunction in adults over age 55 years: a study in an urban US community. Ach Intern Med1990;150: 785-7.

8. Singer PA, Cooper DS, Levy EG, et al. Treatment guidelines forpatients with hyperthyroidism and hypothyroidism. JAMA 1995;273: 808-12.

9. ANDRES PINTO, D.M.D.; MICHAEL GLICK, D.M.D Oral health considerations Management of patients with thyroid disease. JADA, Vol. 133, July 2002 page 849-858.

10. Shalu Chandna, Manish Bathla1. Oral manifestations of thyroid disorders and its management. Departments of Periodontics and Psychiatry, MM College of Dental Sciences and Research, Ambala, Haryana, India. A Indian Journal of Endocrinology and Metabolism / 2011 / Vol 15 / Supplement 2 page S113-S116.

11. Loevy HT, Aduss H, Rosenthal IM. Tooth eruption and craniofacial development in congenital hypothyroidism: Report of case. J AmDent Assoc 1987;115: 429-31.

12. Young ER. The thyroid gland and the dental practitioner. J Can Dent Assoc 1989;55: 903-7.

13. Muzyka BC. Atrial fibrillation and its relationship to dental care. J Am Dent Assoc 1999;130: 1080-5.

14. Malamed SF. Thyroid gland dysfunction in medical emergencies in the dental office. 5th ed. St. Louis: Mosby; 2000. p. 275-86.

15. Klein I, Levey GS. The cardiovascular system in thyrotoxicosis. In: Braverman LE, Utiger RD, editors. The Thyroid. 8th ed. Philadelphia: Lippincott-Raven; 2000. p. 596-604.

16. Poumpros E, Loberg E, Engstrom C. Thyroid function and root resorption. Angle Orthod 1994; 64: 389-94.

17. Yagiela JA. Adverse drug interactions in dental practice: Interactions associated with vasoconstrictors. Part V of a series. J Am Dent Assoc 1999;130:701-9.

18. Galletti PM, Joyet G. Effect of fluorine on thyroidal iodine metabolism in hyperthyroidism.J Clin Endocrinol Metab1958;18: 110210. 
19. Little JW. Thyroid disorders. Part I: hyperthyroidism. Oral Surg Oral Med Oral Pathol Oral Radiol Endod 2006; 101: 276-84.

20. Little JW. Thyroid disorders. Part II: hypothyroidism and thyroiditis. Oral Surg Oral Med Oral Pathol Oral Radiol Endod 2006; 102: 148-53.

21. Malamed SF. Medical emergencies in the dental surgery. Part 1: Preparation of the office and basic management. J Ir Dent Assoc 2015; 61: 302-8.

How to cite this Article: Anas Al-Yasiry M.Sc ${ }^{1}$ Zainab Mahmood Al-Jammali M.Sc ${ }^{2}$, Oral Manifestation for Patients with Thyroid Dysfunction and it's Management in Dental Clinic -A Review Int. J. Drug Res. Dental Sci., 2020; 2(1): 23-26.

Source of Support: Nil, Conflict of Interest: None declared.

Received: 24-1-2020 Revised: 25-2-2020 Accepted: 15-3-2020 